\title{
Electrical Resistivity Investigation of the Bedrock Geometry of the Northern Sector of Kujama Prison Farm Kaduna, Nigeria
}

\author{
Esther O Ocheja ${ }^{1}$, Matoh D Dogara ${ }^{1}$, Hyacinth O Aboh ${ }^{1}$ and Amina M Dawai ${ }^{1}$ \\ ${ }^{1}$ Department of Physics, Faculty of Science, Kaduna State University, P.M.B, 2109, Kaduna, Nigeria. \\ Corresponding E-mail: onechojo@yahoo.com \\ Received 13-12-2020 \\ Accepted for publication 07-04-2021 \\ Published 13-04-2021
}

\begin{abstract}
An electrical resistivity investigation was carried to investigate the bedrock geometry of the northern part of Kujama Prisons Farm Kaduna using the Vertical Electrical Sounding (VES) method. The study is aimed at obtaining information on the subsurface layering for future civil engineering works. The area covered was $200,000 \mathrm{sqm}$ having five (5) profiles with six (6) geophysical investigative points on each profile and separated $100 \mathrm{~m}$ apart. Ohm-Mega resistivity meter was used for the Vertical Electrical Sounding (VES) and Thirty (30) points where established. To interpret the VES data, Res1D iterative software, Surfer 11 and Oasis Montaj software's were used and it revealed three to five subsurface layers having Topsoil thickness between $0.3-2 \mathrm{~m}$ and resistivity between $104-4824 \Omega m$ also, the last layer considered as the weathered/fractured/fresh basement has an infinite thickness with resistivity ranging from $45-10173 \Omega \mathrm{m}$ and the average overburden thickness of the area found to be $17.8 \mathrm{~m}$. The VES found fresh basement at points $A 3(6151 \Omega m), A 6(5089 \Omega m), B 3(1067 \Omega m), E 5(10173 \Omega m)$ and $E 6(1100 \Omega m)$. From the study it is suggestive that the bedrock geometry has been irregularly configured over geological times due to effects of intense weathering. Therefore, the investigation revealed the study area may be considered for civil works of low bearing capacity.
\end{abstract}

Keywords: Bedrock Geometry; Vertical Electrical Sounding; Resistivity; Kujama Prison Farm

\section{INTRODUCTION}

$\mathrm{G}$ eophysics is playing a very significant role as it provides an efficient and cost-effective means of collecting geologic information. Various techniques can be used to help determine the hydro stratigraphic framework, depth to bedrock, extent of ground water contaminant plumes, location of voids, faults or factures, location of abandoned wells, and the presence of buried materials, such as steel drums, tanks, or pipelines. Generally, collecting data without invading or non-destructively from a preferred area is a major concern in any geophysical exploration $[1,2]$. To achieve the best in terms of planning and management of the environment, great knowledge of the subsurface environment has become very critical in construction engineering, resource exploitation and exploration. Little knowledge of the subsurface site whether in construction engineering or resource exploration has often results in catastrophic consequences of seismic activities, disturbance of natural environmental phenomena, contamination and rupturing. Application of geophysical methods in geotechnical investigations has the capability of bringing out the subsurface image of a site which is very essential to the project decision and management [3]. It must 
be admitted that lack of knowledge of the subsurface strength distribution of a location either for erecting a structure or excavation is in disguise a risk to the inhabitants and people living in its environment. Normally, questions pertaining the foundation of buildings come to the fore when issues of buildings submerging under their load arise at a later time; or the collapse of deep wells, tunnels, dam walls, mining sites or caves have brought about questions on the available data or knowledge of the subsurface structures in such locations. Early detection of conditions that may pose potential danger to subsurface areas of interest can be accomplished with geophysical survey. Undetected cavities, fissures and other near surface features such as high clay content that serves as sources and risk to buildings and subsurface activities put up without any geotechnical investigations.

DC resistivity and Electrical resistivity tomography methods are among the most commonly employed geophysical techniques in near surface exploration for natural resources, geotechnical evaluation and environmental assessment [4]. The geoelectrical resistivity imaging technique is also increasingly becoming popular in environmental and engineering investigations [5]. 2D multielectrode electrical imaging system which simultaneously takes into accounts sounding and profiling has successfully been applied to map areas with fairly complex geology [6]. Depending on how the survey is designed and carried out, the DC Resistivity and Electrical Resistivity Tomography can be used to acquire data that will give subsurface images in either two or three dimensions. Lately because automated data acquisition systems and efficient user-friendly inversion softwares are accessible, the electrical resistivity imaging technique has the potential to give more reliable images of the subsurface [3]. The DC resistivity method has wide variety of applications with the objective to determine the physical parameters of a rock formation and map geologic structures in mineral and groundwater exploration and also investigate the subsurface [3,7]. Subsurface geology in geotechnical and environmental assessments is generally heterogeneous and multi-scale such that the physical properties vary both vertically and laterally.

In the light of the above this study, was set out to investigate the bedrock geometry of the northern part of the Kujama prison farm to provide information for civil works.

\section{Location of the Study Area, Geology and Method}

The Kujama prison farm is located at the heart of Kujama which is the capital of Chikun Local Government Area (Fig. 1) and its geographical coordinates of latitude and longitude lies between $10026^{\prime} 23.30^{\prime \prime} \mathrm{N}$ to $10027^{\prime} 10.30^{\prime \prime} \mathrm{N}$ and 70 $34^{\prime} 02$. $0^{\prime \prime} \mathrm{E}$ to $7036^{\prime} 52.30^{\prime \prime} \mathrm{E}$ (Fig. 2). Kujama is lying on a gentle undulating plain ranging from $450-650 \mathrm{~m}$ above sea level underlined by the crystalline basement complex of the Precambrian age. The area and its environs are situated on a lowland area alike. In some parts of the area, there exist some outcrops of hard resistant granite rocks which are basically the result of weathering activities on the Precambrian rocks which were exposed by erosion.

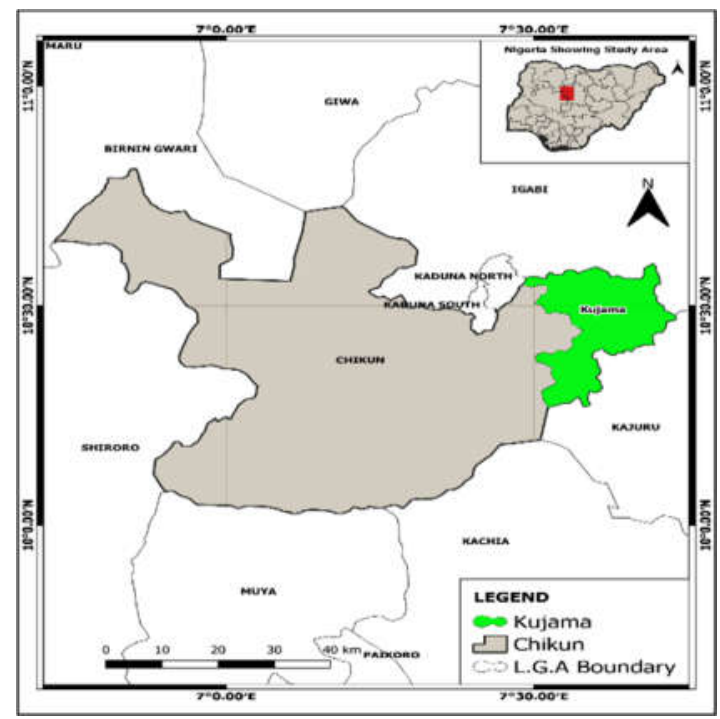

Fig. 1 Geological Map of Chikun Local Government Area, Kaduna State

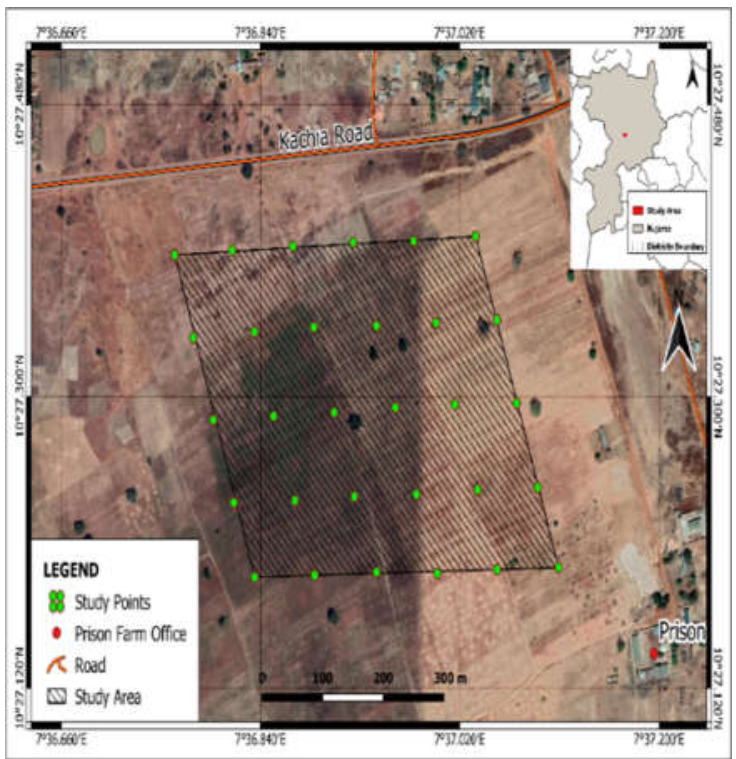

Fig. 2 Map of Study Area Showing the location of the profiles and its Elevation (Inset, Geological map of Nigeria)

Geophysical investigation involving the Vertical Electrical Sounding (VES) was conducted along profiles established at the northern sector of the Kujama prison Farm. Electrical methods use direct currents or low frequency alternating currents to investigate the electrical properties of the subsurface and Electrical resistivity survey is a geophysical survey which consists of injecting electrical current into the subsurface and measuring the electric potential. Great number of electrode spreads have been used in resistivity at various 
times it is advantageous using electrode spreads which requires only one or two electrodes to be moved, and at close spacing where possible, this is to minimize the difficulty of moving stakes with great lengths of wire attached [8]. Schlumberger array of electrical resistivity imaging was used along five (5) profiles with six (6) VES on each profile making a total of thirty (30) VES points. A direction of EW-NS azimuth was employed in the orientation of all the profiles. The direction was employed to ensure a desirable field space for the work.

Each profile length was $500 \mathrm{~m}$ and the interval station used was $100 \mathrm{~m}$. At each VES station, the maximum separation of current electrodes $(\mathrm{AB} / 2)$ was $100 \mathrm{~m}$. The arrangement of electrodes which was employed in this work is shown in Fig. 3; A and B represent the current electrodes through which the current was passed into the ground; C and D represent the potential electrodes across which the potential difference caused by the current was measured.

The field procedure involves expanding the current electrodes spread while keeping the potential electrode spread relatively fixed. For each reading, the current was sent into the ground through $\mathrm{A}$ and $\mathrm{B}$, which set a potential difference between the potential electrodes $\mathrm{C}$ and $\mathrm{D}$. The magnitude of the potential difference developed was a measure of the electrical resistance of the ground between the potential electrodes. This resistance is in turn a function of the geometrical configuration of the electrodes and the electrical parameters of the ground [9].

\section{THEORY OF ELECTRICAL RESISTIVITY}

Many electrode configurations have been designed, although several are occasionally employed in specialized surveys, two are in common use, these are the Wenner and Schlumberger array [10].

Considering Fig. 3, where the current sink is a finite distance from the source, the potential $(V c)$ at an internal electrode $\mathrm{C}$ is the sum of the potential contributions $(V A)$ and $(V B)$ from the current source at $\mathrm{A}$, and the sink at $\mathrm{B}$.

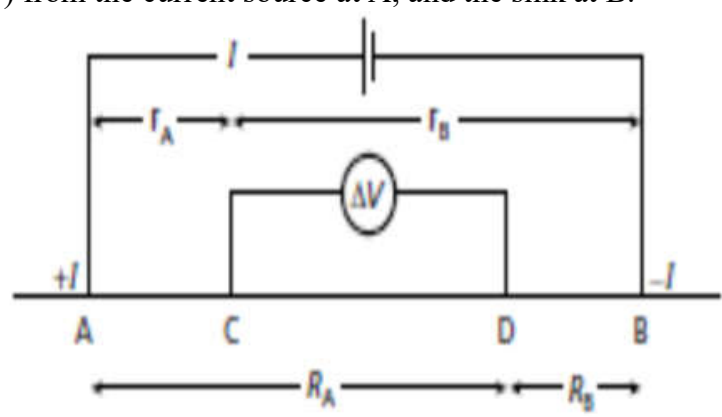

Fig. 3 The generalized form of the electrode configuration used in resistivity measurements

$V_{C}=\mathrm{V}_{\mathrm{A}}+\mathrm{V}_{\mathrm{B}}$

The potential gradient associated with this current density is $\frac{\partial V}{\partial r}=-\frac{\rho I}{2 \pi r^{2}}=-\rho J$

The potential $\left(V_{r}\right)$ at distance $r$ is then obtained by integration

$V_{r}=\int \partial V=-\int \frac{\rho I \partial r}{2 \pi r^{2}}=\frac{\rho I}{2 \pi r}$

Equation (3) can be written as

$V_{C}=\frac{\rho I}{2 \pi}\left[\frac{1}{A C}-\frac{1}{C B}\right]$

Absolute potentials are difficult to monitor, so the potential difference $(\Delta V)$ between electrodes $\mathrm{C}$ and $\mathrm{D}$ is measured. The potential difference is then given by:

$\Delta V=\mathrm{V}_{\mathrm{C}}-\mathrm{V}_{\mathrm{D}}=\frac{\rho I}{2 \pi}\left[\left(\frac{1}{A C}-\frac{1}{C B}\right)-\left(\frac{1}{A D}-\frac{1}{B D}\right)\right]$

$\rho_{a}=\frac{2 \pi \Delta V}{I}\left[\left(\frac{1}{A C}-\frac{1}{C B}\right)-\left(\frac{1}{A D}-\frac{1}{B D}\right)\right]^{-1}$

Hence,

$\rho_{a}=R K$

Where,

$K=\frac{2 \pi}{\left(\frac{1}{A C}-\frac{1}{C B}\right)-\left(\frac{1}{A D}-\frac{1}{B D}\right)}$

Where $\mathrm{R}$ is resistivity, i.e $R=\frac{\Delta V}{I}$, and $\mathrm{K}$ is called geometrical factor which depends on the arrangement of the four electrodes. This factor can be obtained using the Laplace equation in polar coordinates to derive the electrical potential functions around the source ( $\mathrm{A}$ and $\mathrm{B}$ ) and measuring ( $\mathrm{C}$ and $\mathrm{D})$ electrodes [11]. While (AC), (BC), (AD), and (BD) are the distances in meters between the respective electrodes, when $(A C)=(B D)$ and $(B C)=(A D) ;$ From [12], $\mathrm{K}$ can be defined as,

$K=\pi \frac{[A C][A D]}{[C D]}$

In the Schlumberger configuration (Fig. 4), the current and potential pairs of electrodes often also have a common midpoint, but the distances between adjacent electrodes differ.

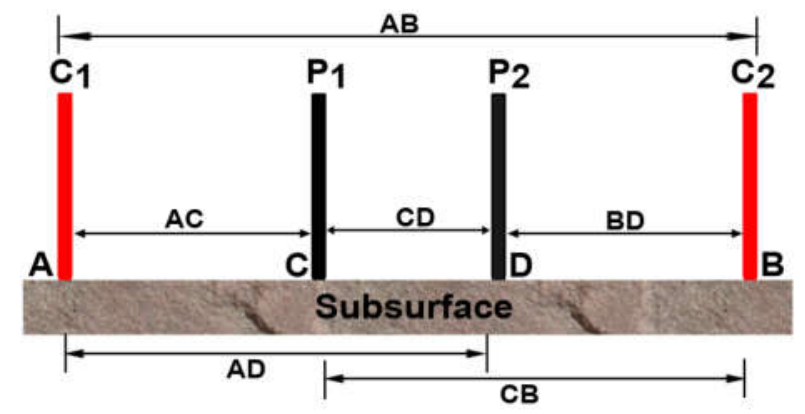

Fig. 4 Schlumberger Electrode Array 


\section{DATA PROCESSING AND INTERPRETATION}

In interpreting the apparent resistivity of the sounding curves, the first thing to note is the curve shape [13]. This curve allows us to determine the model parameters like initial model layers and the curve types (such as A, H, K, Q, KH, HA-type) of the study area [8]. The values of apparent resistivity obtained are plotted on a log-log graph (field curve), the $\mathrm{x}$ - and $\mathrm{y}$-axes of which represent the logarithmic values of the current electrode half-separation $(\mathrm{AB} / 2)$ and the apparent resistivity $\left(\rho_{a}\right)$, respectively to estimate the depth and resistivities of the bed rocks using Res1D software. In order to obtain typical resistivity sounding curves for the area a computer Iteration Software Res1D (version 1.00.07 Beta) with initial model parameters which gave inversion results was used (Fig. 5 and Table I). The vertical electrical sounding interpreted data was used to obtained geoelectric and geologic section using Surfer 11 for geoelectric sections and Oasis montaj for the maps (Fig. 7-10).

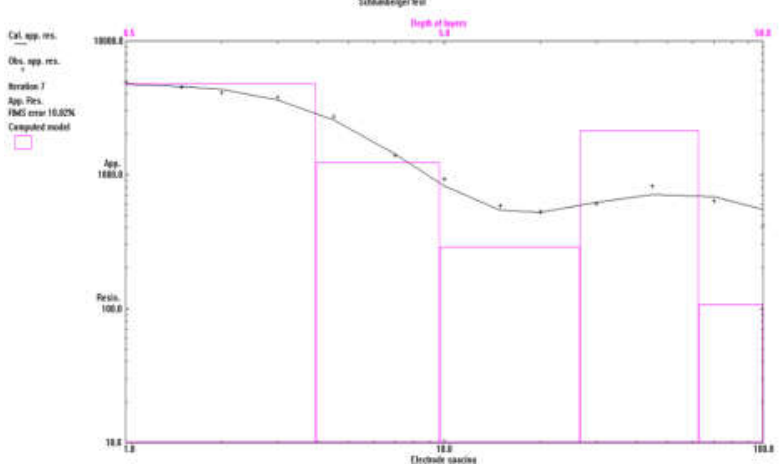

Fig. 5 Typical Resistivity Curve (A4) using Res1D Iterative Software

TABLE I LAYER MODEL.

\begin{tabular}{cccc}
\hline Layer & Resistivity & Thickness & Depth \\
\hline 1 & 4824.058 & 1.977 & 2.0 \\
2 & 1238.352 & 2.856 & 5.0 \\
3 & 289.432 & 8.512 & 14.0 \\
4 & 2136.468 & 18.007 & 32.0 \\
5 & 106.558 & &
\end{tabular}

\section{RESUlts AND DisCUSSIONS}

In geophysics, the expression of acquired field data into geological terms is what makes the field measurement relevant. Just like any other geophysical method, the interpretation obtained from the results of Vertical Electrical Sounding (VES) data involves the expression of acquired field data into geological terms and when the results of the field data are interpreted, information such as depth, resistivity and the thickness of the subsurface geometry can be obtained.

In interpreting the apparent resistivity of the sounding curves, the first thing to note is the curve shape [13]. Before applying more complicated methods of interpretation, it is important to consider a few rough ideas. This curve allows us to determine the model parameters like initial model layers and the curve types (such as A, H, K, Q, KH, HA-type) of the study area [8]. The values of apparent resistivity obtained were plotted on a graph (field curve), the $\mathrm{x}$ - and $\mathrm{y}$-axes of which represent the logarithmic values of the current electrode halfseparation $(\mathrm{AB} / 2)$ and the apparent resistivity $\left(\rho_{a}\right)$, respectively to estimate the depth and resistivities of the bed rocks using Res1D software.

In order to obtain typical resistivity sounding curves for the area a computer Iteration Software Res1D (version 1.00.07 Beta) with initial model parameters which gave inversion results was used (Fig. 5). The sounding interpreted data was used to obtain geoelectric and geologic sections (Fig. 6) as an example and corresponding table II which shows the typical resistivity values of rock and soil types compiled in different basement area from different author in Kaduna State.

TABLE II RESISTIVITY VALUES OF ROCKS AND SOIL TYPES USED IN INFERRING THE GEOLOGIC SECTIONS OF THIS WORK $[1,14,15$,

\begin{tabular}{ll}
\multicolumn{2}{c}{$16,17]}$. \\
\hline Soil and Rock Types & Resistivity $(\boldsymbol{\Omega m})$ \\
\hline Topsoil/Sandy Soil & $66-800$ \\
Clayey/ Silty Clay/Clayey Sand & $80-700$ \\
Weathered Laterite & $801-1800$ \\
Indurated Laterite & $1801-8500$ \\
Weathered Basement & $26-223$ \\
Fractured Basement & $500-1000$ \\
Fresh Basement & $>1000$ \\
\hline
\end{tabular}

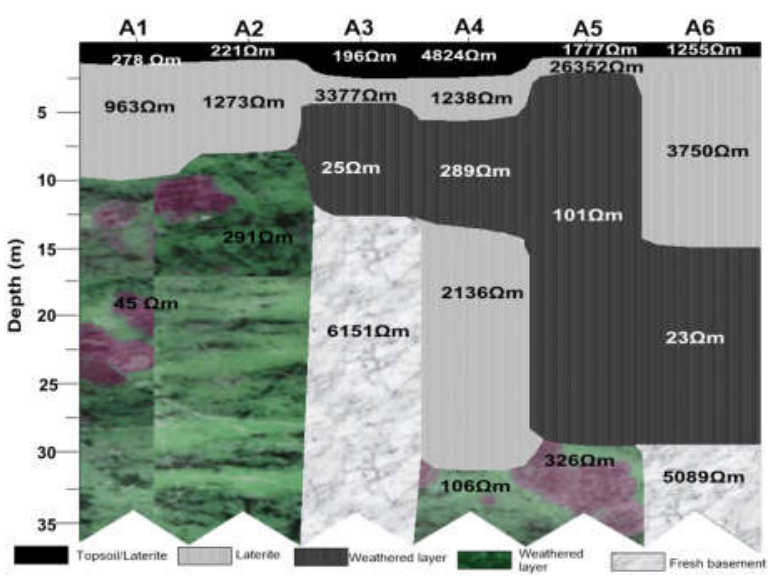

Fig. 6 Geoelectric/geologic section of Profile A 


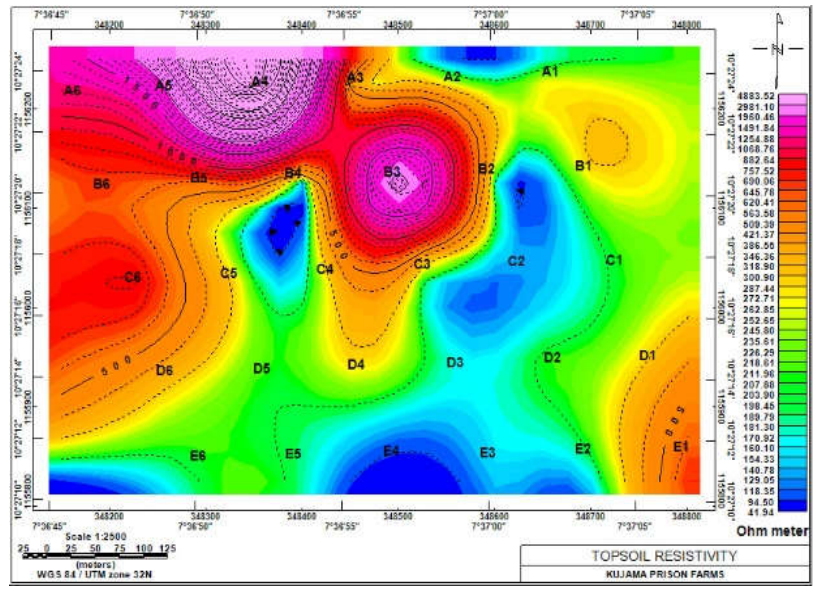

Fig. 7 Map of the Topsoil/ First Layer Resistivity

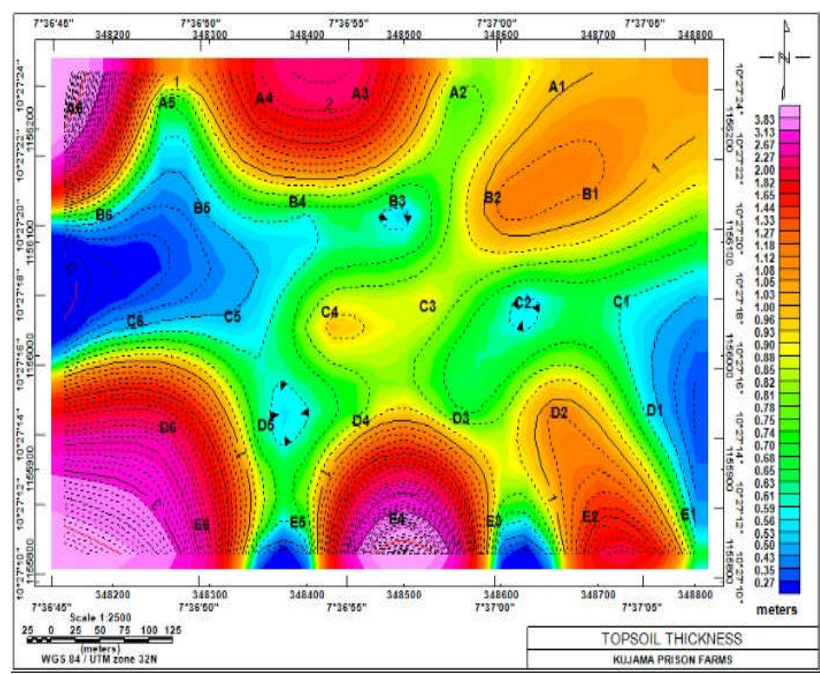

Fig. 8 Map of the First Layer Thickness

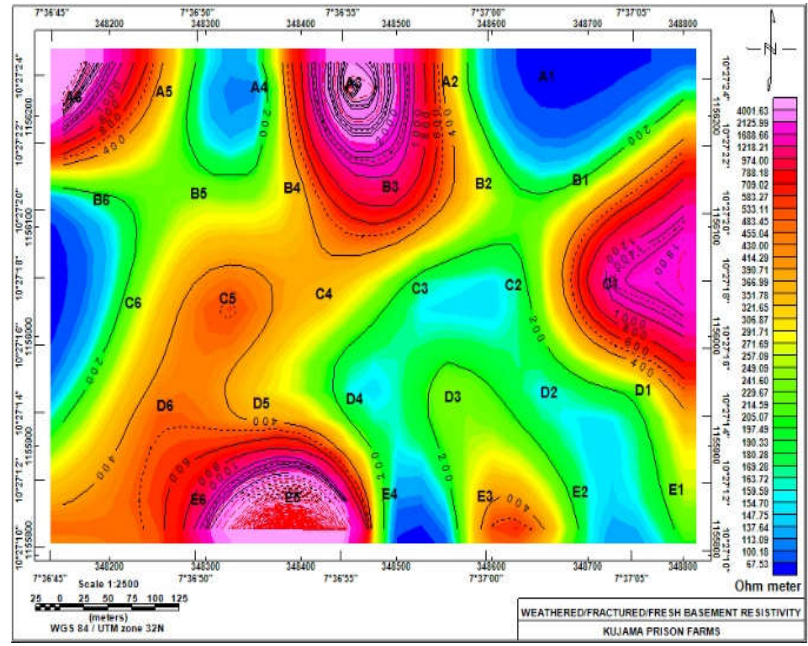

Fig. 9 Map of the Weathered/Fractured/Fresh Basement Resistivity

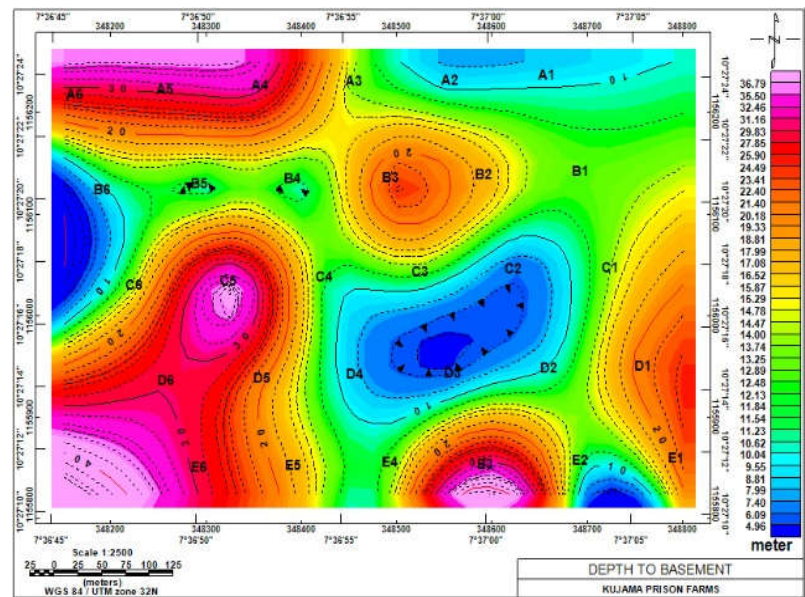

Fig. 10 Map of Depth to the Basement

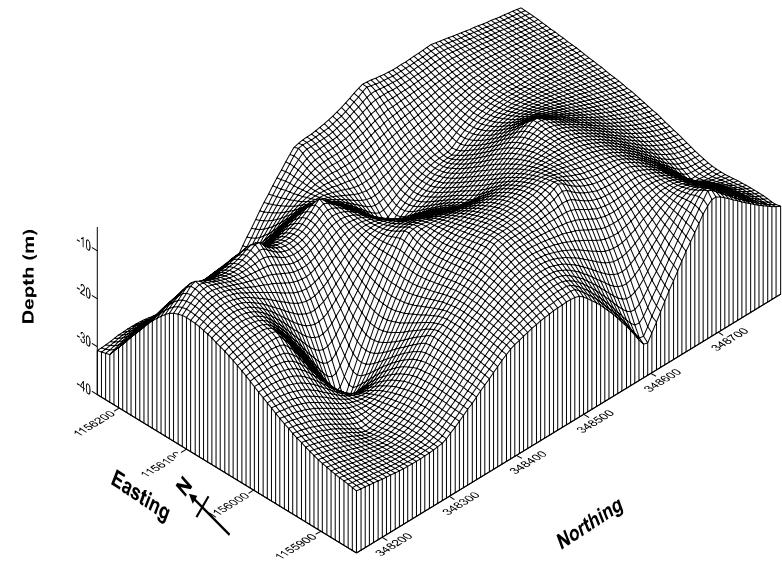

Fig. 11 3-Dimension Map of Depth to Basement

The geoelectric sections for the five Profiles revealed that the area is underlain by three to five layers having resistivity range from $104-4824 \Omega m$ respectively of which the first layer is the topsoil consisting of sand/clay, laterite, the second layer also consist of sand/clay, weathered/indurated laterite, the third to the fifth layer is made up of the weathered/fractured/fresh basement of which only few points actually reached the fresh basement and having resistivity range from $45-10173 \Omega \mathrm{m}$. VES point C5 and D6 from the maps shows there are fractures within the layers subsurface.

Based on the resistivity values of the different geoelectric layers and the various geologic units obtained the geometry of the subsurface can be qualitatively evaluated from the layer resistivity. The bedrock geometry is irregular with high depth around $\mathrm{C} 5$ and the basement is shallow almost throughout the entire study area. The low resistivity associated with the regions of basement uplift may be as a result of intense weathering of the fresh basement over geological times. From Fig. 11 the geometry of the Northern sector of the Kujama 
Prison Farm dips from East Central to the Southern part also, part of the North and West and there is an uplift at the edges of the North West, South West and the East.

\section{CONCLUSION}

The interpretation of Vertical Electrical Sounding (VES) data of the geophysical investigation of the study area, VES has revealed on the average three to five subsurface geoelectric layers and geologic sections with evidence of fractures on VES points C5 and D6.

The bedrock geometry of the Northern Sector of the Kujama Prison farm shows irregularity but on the average the depth of the entire area may be recommended for foundation design, engineering structural and other related works but the need for further investigation is highly necessary. The regions for these should be areas where the basement materials are highly resistive and with a shallow depth to basement. For this work these areas are VES A3, VES A6, VES C1 and VES E5 however further investigation is required. This article successfully described the bedrock geometry of the Northern sector of Kujama Prison Farm Kaduna as an area with irregular bedrock geometry due to intense weathering of the fresh basement over time based on the interpreted data.

\section{References}

[1] L. N. Mohammed, H. O. Aboh, and E. A. Eminike, "A Regional Geoelectric Investigation for Groundwater Exploration in Minna Area". Science World Journal, vol. 2, no. 3, pp. 15-19. 2007.

[2] J. Olona, J. A. Pulgar, G. Fernandez-Viejo, C. LopezFernandez, and J. M. Gonzalez-Cortina, "Weathering variations in a granitic massif and related geotechnical properties through seismic and electrical resistivity methods". Near Surface Geophysics, vol. 8, no. 6, pp. 585-599, 2010.

[3] A. A. Aning, P. Tucholka and S. K. Danuor, "2d Electrical Resistivity Tomography (Ert) Survey Using the Multi-Electrode Gradient Array at the Bosumtwi Impact Crater, Ghana". Journal of Environment \& Earth Science, vol. 3, no. 5. 2013.

[4] R. Benson, and L. Yuhr, "Site Characterization Strategies: Old and New". In Second Annual Conference on the Application of Geophysical and NDT Methodologies to Transportation Facilities, Federal Highway Ad-ministration, April, 2002, pp. 15-19. Bull 31:101

[5] D. K. Butler, "Near-surface geophysics". Society of Exploration Geophysicists Tulsa, 2005.

[6] A. P. Aizebeokhai, A. Olayinka and V. Singh, "Application of 2d and 3d Geoelectrical Resistivity Imaging for Engineering Site Investigation in a Crystalline Basement Terrain, South-western Nigeria". Environmental Earth Sciences, vol. 61, no. 7, pp. 1481-1492, 2010.
[7] N. Andrews, A. Aning, S. Danuor and R. Noye, "Geophysical Investigations at the Proposed Site of the KNUST Teaching Hospital Building using 2d and 3d Resistivity Imaging Techniques". Int. Res. Jour. Geol. Min, vol. 3, no. 3, pp. 113-123, 2013.

[8] W. M. Telford, L. P. Geldart, and E. R. Sheriff, Applied geophysics. 2nd Ed, Cambridge University Press, 1990.

[9] K. K. Akau, 'Geoelectric Characterization of the Sub Surface at Unguwan Maji, Dan Hono in South Eastern Part of Kaduna Millennium City, Kaduna State', An unpublished MSc Thesis, Department of Physics, Kaduna State University, 2017.

[10]M. John, "Field Geophysics; Third Edition. University College London: John Wiley and Sons Ltd, 2003.

[11] G. V. Keller and F. C. Frischknecht, "Galvanic resistivity methods, in Electrical methods in geophysical prospecting, International series of monographs in electromagnetic waves, vol. 10, edited by A. L. Cullen, V. A. Fock and J. R. Wait, pp. 90-91, Pergamon Press, New York, 1966.

[12]P. Kearey, M. Brooks, and I. Hill, "An Introduction to Geophysical Exploration. Third Edition, 2002.

[13] J. O. Alao, "Delineation of The Interfacial Configuration in A Section of Millennium City, Kaduna”. An unpublished MSc Thesis, Department of Physics, Kaduna State University, 2017.

[14] N. K. Abdullahi, E. E. Udensi, A. Iheakanwa and B. E. Eletta, "Geo-electrical Method Applied to Evaluation of Groundwater Potential and Aquifer Protective Capacity of Overburden Units". British Journal of Applied Science \& Technology, vol. 4, no. 14, pp. 2024-2037, 2014.

[15] M. D. Dogara, "A geophysical study of part of Kuri river basin Lere-Kauru area of Kaduna state and its hydrogeological. Unpublished Ph.D. Thesis Ahmadu Bello University, Zaria, 2003.

[16]B. S. Jatau, S. I. Fadele, And A. G. Agelaga, "Groundwater Investigation in Parts of Kaduna South and Environs using Wenner Offset Method of Electrical Resistivity Sounding". Journal of Earth Sciences and Geotechnical Engineering, vol. 3, no. 1, pp. 41-54, 2013.

[17] A. O. Talabi, and K. O. Ayodeji, "Vertical Electrical Resistivity Sounding for Groundwater in Bishini Area Kaduna State". IMPACT: International Journal of Research in Applied, Natural and Social Science, vol. 3, no. 1, pp. 1-8, 2015. 